\title{
Prophylactic Rules for Newborns, Babies, Children and Adults in problems of Hip, Knee, Shank, Feet and Spine
}

\author{
Tomasz Karski ${ }^{1 *}$, Jacek Karski², Katarzyna Karska ${ }^{2}$, Klaudia Karska² and Honorata Menet ${ }^{3}$ \\ ${ }^{1}$ Vincent Pol University, Lublin, Poland
}

${ }^{2}$ Medical University in Lublin, Poland

${ }^{3}$ The University of Normandy in Caen, France

*Corresponding author: Tomasz Karski, Poland

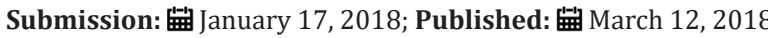

\begin{abstract}
Summary
It is very frequent that the achievement of positive treatment results for many illnesses and deformities in children, youth and adults is difficult or even impossible. It is due to the fact that the prophylactics is sometimes difficult to explain and patients either do not know what to do exactly or doubt the effectiveness of the doctor's recommendations. In the article authors, present their material, observations (T. Karski - orthopedic experience 57 years), and recommendations for easy and verified prophylactic methods for spine, hips, knees, shanks and feet in children, youth and adults [1-11].

Keywords: Prophylaxis; Hips; Knees; Shanks; Spine; Children; Adults
\end{abstract}

\section{General Recommendations}

\section{Breast feeding}

It should be constant and regular during the first year or the first two years. It satisfies the important need of nutrition and emotional contact with the mother. The very notion of breast feeding translates into German as stillen which means to calm down, soothe and cheer up. It has been confirmed that breast feeding plays a very important psychological role in development of babies and children.

\section{Prohibition of hat tying}

Under the child's chin for the first 4 years. Tying the head obstructs the free flow of blood to the brain, but especially the "flow back" from the brain to the heart though the external jugular vein (both vena jugularis superficialis). According to ours observations - such situation repeated on a daily basis during the first months or years of life can lead to abnormalities in development of circular system in the brain. Such hat tying is common in Poland and other Slave Nations, but not in Germany, England, in USA (personal experience of Katarzyna Karska and Honorata Menet).

\section{Holding/carrying the baby}

constant contact of the child with the mother and father stimulates positively and soothes the child. Holding and a close contact the baby at night is very important since it eliminates possible stress the baby may experience. Stress has a very negative influence since it closes the capillaries. It causes cerebral asphyxia and may lead to anomalies of circulatory system. Here - we want to make the readers attention - in adults age - stress also close the capillaries and is the cause of heart pain.

Orthopedic recommendations for babies, youths and adults

Carrying the baby: Should be performed only with the baby facing the parent with maximal abduction and flexion of the hips that is legs should always be in a frog position, bottom down, knees up. Parents mustn't carry your baby with its back to own body, since it may cause hip dysplasia (!). Children need one year for proper development of the hips. Such close contact with parents, facing the parents' heart also has a positive psychological impact. What is more, this proper way of carrying the child simultaneously prevents the fixation or the development of wry neck (muscular torticollis). The baby's head should be easily twisted / rotated to the side affected by torticollis, to make stretching of the shortened muscle sterno - cleido - mastoideus. Only such treatment can prevent the necessity for operations of wry neck. This method was introduced in 1974 by T. Karski (publication in Orthopädische Praxis in Germany in 1991 and in American Research Journal of Medicine and Surgery in 2016). 
Standing up and walking of the small child: Is allowed only after the first birthday of the baby. Sometimes the children want to stand earlier which may be the symptom of Minimal Brain Dysfunctions (MBD). See - publication in Czech Republic in 2016. Too early standing of the child is because of extension contracture of the trunk muscles one of the symptoms of MBD. Allowing the baby to stand before the age of 12 months can lead to enlarge of varus deformity of shanks and is harmful for the development of hips.

Varus deformity of the shanks in small children: ("O" shaped deformity of the shanks) can be easily prevented the worsening or full cure when the baby is not allowed to stand and walk for $2-4$ months. This treatment can be used in children aged from 1 year to 2.5. For treatment the child is carried all the day or plays on the floor. Additionally, to the child should be administered proper doses of Vitamin D3 (the best is Vigantol). After 2 - 4 months of such nursing the axis of the shanks will spontaneously return to its anatomical axis. These observation are publish in Germany and in USA (T. Karski \& J. Karski - see literature).

Valgus deformity of the knees in small children: (" $\mathrm{X}$ " shaped deformity) can be prevented when to the child is not allowed to sit in a position with in-turning of the legs - in orthopedic language - the "TV sitting" (other words "Indian sitting" - in German "Najadensitz"). Sitting cross-legged (tailor sitting) is good but sitting in "a butterfly position" (the term is taken from karate) is even better- it means that the knee should be in flexion and directed to the sides. In this position the hips are positioned in full abduction, what allowed the best its development.

Toes - in" walking of children: Is caused by incorrect way of sitting and can be prevented as is described in point 4 . The explanations is: the sitting in a TV-position with internal rotation of the hips, causes not only the valgus deformity of the knees but also changes the model of hips movements - that is - diminishes external rotation, makes bigger internal rotation, can also enlarge the antetorsion (AT) of femoral neck and heads - and, what mentioned above, the incorrect- "toes in" walking.

Sitting of children: Should be in a position with the feet together and with the knees maximal apart to the sides, what is very positive for the hips, reduces the antetorsion, protects the spine against scoliosis (spine is relaxed - please to paid particular attention - that in "S" scoliosis (I etio - pathological - group [epg] in Lublin classification) and in "I" scoliosis (III epg) spine is primary in full extension position and stiff. Proper sitting (relax) prevents also valgus deformity of the knees (for details see point 4).

Sitting of children with relaxed spine: The spine should be slightly bend, there is in flexion position. No more in all countries the children mustn't be instructed to sit with their back straight. The old recommendation - "sit straight up". Was spoken to the children over years. No - such sitting can fixed the extension contracture of spine - and this position can facilitate / make easy the development of the scoliosis (T. Karski - see literature).
Children with posture deformities: In this deformity the anterior tilt of the pelvis is observed, that is the buttocks are pushed to the back, the abdominal region is moved to the front and lumbar spine is an excessive hyperlordosis. Children suffering from this deformity require urgent treatment. This posture deformity is common in children with Minimal Brain Dysfunction (MBD) and ADHD (Attention Deficit Hyperactivity Disorder). Treatment recommendations: lying on the stomach (in prone position) with the knees flexed for 90 degree for 2-3 hours every day, e.g. while watching TV. This exercise should be repeated daily over many months or years (!). Other method of treatment for older children includes practicing karate, or taekwondo, aikido, and yoga for stretching of the m. rectus (this muscle is one of the four parts of $\mathrm{m}$. quadriceps - extensor of the knee and flexor of the hip).

Prohibition of jumping and skipping on a hard surface: For the children aged between 4 and 11 years old. Such behavior is typical for the children with MBD and ADHD symptoms. Jumping may cause necrosis of the femoral head, that is Legg-CalvéWaldenström-Perthes disease. Such repeated jumping cause firstly the fracture of the bones in femoral head (cartilage is resistant) and this start the whole process of necrosis. Here we want to remind that this "traumatic causes" described also Legg, Calve and Salter from Toronto / Canada. The article about children with MBD and ADHS is described in 2017 in Czech Republic (T. Karski, J. Karski, J. Pyrc).

Prohibition of standing 'at ease' on the right leg in children and adults: Standing on the right leg develops and fixes scoliosis. The etiology of scoliosis and the recommendations of new treatment (1995-2007) were described in detail by T. Karski in 1995 - 2007 and present in website www.ortopedia.karski.lublin. $\mathrm{pl}$ See also articles published in USA in last years. According to the new classification (T. Karski 1995 - 2007) there are three groups and four types of scoliosis:

a. "S" double scoliosis is connected with walking and standing 'at ease' on the right leg.

b. "C" and "S" types of scoliosis - the cause is only standing 'at ease' on the right leg.

c. "I" scoliosis - clinically is only stiffness of the spine, there are no curves or very small ones - the cause is only gait.

In adults every type of scoliosis, because of the standing 'at ease' on the right leg - enlarged and become to be degenerative. We would like to make attention - that the permanent standing 'at ease' on the right leg in every person is the cause not only the degenerative changes in spine but also the cause of pain in the right hip and sometimes in knee.

For adults we recommend a very simple and effective method of treatment and prophylactics. All patients aged over 50 years should changed own standing, walking, sitting and sleeping position.

They should stand in abduction of 20-30 degree and in internal rotation (toes in) of 10 - 20 degree (like in Karate), walking should 
be in abduction - feet apart 20 - $30 \mathrm{~cm}$ (like sailors), sitting should be with the knees together, feet wide apart (like young girls), sleeping -in prone position with the affected leg in abduction and in flexion - one part of the night and in embryo position for spine during the other part of the night. See the articles about "Imperfect Hips ..." publish in USA.

Every driver or passenger of small cars: Should go out from the car only on both legs / feet. Getting off the car on one leg / foot is the cause of distortion syndrome of ankle joint, knee and in some special cases also in hip joint (if in this joint were primary arthrosis symptoms and the movement was limited). The rules of prophylaxis are described in other Grimsom Publishers Journal in 2017 and in American Research Journal of Medicine and Surgery (2017).

\section{References}

1. Karski T, Wośko I (1976) Problem der Ätiologie, Prophylaxe und Behandlung des muskularen Schiefhalses bei Kindern. Beiträge zur Orthopädie und Traumatologie 12: 701-706.

2. Karski T (1991) Frühestbehandlung des muskul ren Schlefhalses durch Torsionslagerung. Orthopädische Praxix 27: 691-695.

3. Karski T, Karski J (1992) Überlastungen und Marschäden bei der Pilgerfahrt zur Schwarzen Madonna. Orthop Praxis 4: 286-289.

4. Karski T (2014) Biomechanical Etiology of the So-called Idiopathic Scoliosis (1995-2007)- Connection with Syndrome of Contractures-
Fundamental Information for Pediatricians in Program of Early Prophylactics. Surgical Science 5: 33-38.

5. Karski T, Jacek K (2015) Biomechanical etiology of the so-called Idiopathic Scoliosis (1995 - 2007). Causative role of gait and permanent standing 'at ease' on the right leg. New classification. Principles of new therapy and causal prophylaxis. Canadian Open Medical Science \& Medicine Journal 1(1): 1-16.

6. Karski T, Karski J (2015) Syndrome of Contractures and Deformities according to Prof. Hans Mau as Primary Cause of Hip, Neck, Shank and Spine Deformities in Babies, Youth and Adults. American Research Journal of Medicine and Surgery 1(2).

7. Karski T, Jacek K (2015) Biomechanical etiology of the so-called Idiopathic Scoliosis (1995 - 2007). Causative role of gait and permanent standing 'at ease' on the right leg". New classification. Principles of new therapy and causal prophylaxis. Canadian Open Medical Science \& Medicine Journal 1(1): 1-16.

8. Karski M, Tomasz K, Jarosław Pyrc, Małgorzta Kulka (2016) Deformations of the Feet, Knees, Hips, Pelvis in Children and Adults with Minimal Brain Dysfunction. Causes. Treatment. Prophylaxis. Czech Republic, Locomotor System 23(2): 20-31.

9. Karski J, Karski T (2016) "Imperfect hips" As a Problem at an Older Age. Early and Late Prophylactic Management before Arthrosis. Jacobs Journal of Physiotherapy and Exercises 2 (2)1: 015- 17.

10. Jacek Karski, Tomasz Karski, Katarzyna Karska, Jarosław Pyrc (2017) Ankle Joint Pathology of Car Drivers and Passengers. Case report. American Research Journal of Medicine and Surgery 2:12.

11. www.ortopedia.karski.lublin.pl
Creative Commons Attribution 4.0 International License

For possible submissions Click Here

\section{Submit Article}

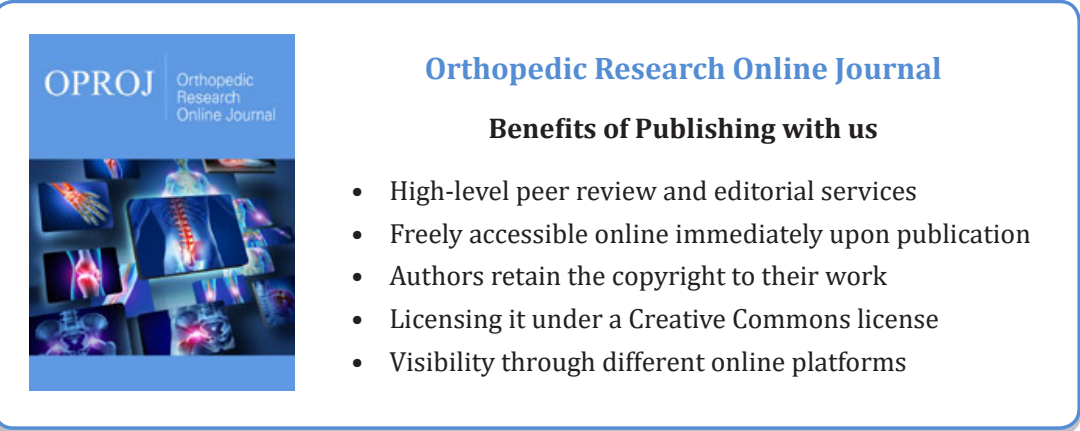

